\title{
Developing the Role of Prehabilitation in Elective Colorectal Surgery
}

\author{
Bethany Malone* \\ Colorectal Surgeons of Pennsylvania, St. Vincent's Hospital, Allegheny Health Network, USA \\ *Corresponding author: Bethany Malone, Colorectal Surgeons of Pennsylvania, St. Vincent's Hospital, Allegheny Health \\ Network, USA
}

\begin{tabular}{|c|c|}
\hline ARTICLE INFO & ABSTRACT \\
\hline Received: 蔧 September 09, 2019 & \\
\hline Published: 幽 September 16, 2019 & $\begin{array}{l}\text { Citation: Bethany Malone. Developing the Role of Prehabilitation in Elective Colorectal } \\
\text { Surgery. Biomed J Sci \& Tech Res 21(3)-2019. BJSTR. MS.ID.003594. }\end{array}$ \\
\hline
\end{tabular}

\section{Editorial}

The largest paradigm shift in the perioperative management of patients has been the implementation of Enhanced Recovery after Surgery Pathways (ERAS). These pathways involve multimodal analgesia, early ambulation, and minimizing the amount of time patients spend NPO. ERAS pathways have been proven time and again to reduce hospital length of stay, improve post-operative quality of life, decrease healthcare costs, and decrease postoperative complications [1]. While ERAS initially began in colorectal surgery, similar protocols have been developed in other areas, such as cardiothoracic surgery, and include further measures such as preoperative smoking cessation. Despite improvements in surgical technology, complication rates following colorectal surgery remain relatively unchanged [2]. Perhaps the next advancement isn't necessarily in surgical technology or technique, but in expanding perioperative management to include the pre-operative period.

The majority of patients undergoing major operations is over the age of 60 . While this demographic has many unmodifiable risk factors for surgery, many of their modifiable risk factors go unaddressed, such as smoking status or nutrition. Measures of cardiopulmonary health, such as exercise testing, predict risk for post-operative complications following abdominal surgery [3]. Prehabilitation programs seek to optimize patients' cardiopulmonary function pre-operatively in order to facilitate their post-operative recovery.

In the field of cardiac surgery, prehabilitation programs have been shown to decrease length of hospital stay after coronary artery bypass surgery and increase patient observed quality of life for up to 6 months post-operatively. These programs typically involve a supervised aerobic exercise program twice weekly for 6-8 weeks before surgery [4]. While supervised programs do ensure patients adhere to the regimen, home based programs with patient selected activities have lower attrition rates than hospital supervised programs [5]. In non-small cell lung cancer patients, a walking program involving walking three times daily for 1 week was shown to decrease length of hospital stay, decrease the amount of time that patients required chest tube drainage, and decrease the amount of post-operative pulmonary complications. While this study only involved a one-week course of a prehabilitation exercise program, other thoracic studies correlate with cardiac studies and show an optimal time of 6-8 weeks of an exercise based prehabilitation program in addition to chest physiotherapy [5].

While a 6-8-week prehabilitation time course is reasonable for cardiothoracic surgery, the mean time between diagnosis and surgical resection for elective colorectal cancer operations is 31 days. When measuring patient cardiovascular fitness using a 6 Minute Walking Test (6MWT), a four-week program including aerobic exercise, whey protein supplementation, and relaxation techniques has been shown to improve patient's 6MWT at the time of operation compared to their baseline before intervention [6]. Prehabilitation programs have not only been shown to improve cardiovascular health but also cancer related outcomes. A recent meta-analysis pooling randomized controlled trials involving elective colon resections in patients with non-metastatic colon cancer showed that prehabilitation was a statistically significant predictor of 5-year disease free survival in stage III colon cancer 
patients. The proposed mechanism is that exercise attenuates the systemic inflammatory response that can contribute to recurrence of unregulated cell growth [7].

The current literature on prehabilitation is fraught with inconsistencies. There is no uniform methodology. Programs can include aspects such as aerobic exercise, resistance training, nutrition supplementation, relaxation and stress management techniques, or smoking cessation. In addition, there is little data to support that prehabilitation programs decrease costs or length of hospital stay after colorectal surgery. Multiple randomized controlled trials are currently under recruitment to study programs such as high intensity interval resistance training or multimodal prehabilitation programs. Further study is definitely necessary at this juncture to better delineate the role and benefit of prehabilitation. Another variable to consider is patient attrition. In the era of multidisciplinary team-based care, will adding a prehabilitation program help to empower patients before treatment or overwhelm patients as an additional check box that they need to worry about before surgery? Despite these questions,

\section{ISSN: 2574-1241}

DOI: 10.26717/BJSTR.2019.21.003594

Bethany Malone. Biomed J Sci \& Tech Res

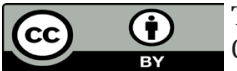

This work is licensed under Creative Commons Attribution 4.0 License

Submission Link: https://biomedres.us/submit-manuscript.php the field of prehabilitation shows promise in improving outcomes after colorectal surgery.

\section{References}

1. Ljungqvist O, Scott M, Fearon KC (2017) Enhanced recovery after surgery: A review. JAMA Surgery 152(3): 292-298.

2. Bokey EL, Chapuis PH, Fung C, Hughes WJ, Koorey SG, et al. (1995) Postoperative morbidity and mortality following resection of the colon and rectum for cancer. Diseases of the Colon and Rectum 38(5): 480486.

3. Levett DZ, Grocott MP (2015) Cardiopulmonary exercise testing for risk prediction in major abdominal surgery. Anesthesiol Clin 33(1): 1-16.

4. Boreskie KF, Hay JL (2019) Prehabilitation. Clinics in Geriatric Medicine.

5. Orange ST, Northgraves MJ, Marshall P, Madden LA, Vince RV (2018) Exercise prehabilitation in elective intra-cavity surgery: A role with the ERAS pathway? A narrative review. Int J Surg 56: 328-333.

6. Chen BP, Awasthi R, Sweet SN, Minnella EM, Bergdahl A, et al. (2019) Four-week prehabilitation program is sufficient to modify exercise behaviors and improve preoperative functional walking capacity in patients with colorectal cancer. Support Care Cancer 25(1): 33-40.

7. Trépanier M, Minnella EM, Paradis T, Awasthi R, Kaneva P, et al. (2019) Improved disease-free survival after prehabilitation for colorectal cancer surgery. Ann Surg 270(3): 493-501.

$\begin{array}{ll}\text { BIOMEDICAL } & \text { Assets of Publishing with us } \\ \text { RESEARCHES } & \text { - Global archiving of articles } \\ & \text { - Immediate, unrestricted online access } \\ & \text { - Rigorous Peer Review Process } \\ \end{array}$

